\title{
Una aproximación al estudio de las políticas públicas de vivienda rural en Tucumán
}

\author{
An approach to the study of rural housing \\ public policies in Tucumá
}

\author{
Ana Garay ${ }^{1}$ y Claudia Fernanda Gómez López ${ }^{2}$ \\ Fecha de recepción: 05-04-2021 - Fecha de aceptación: 21-09-2021 \\ Hábitat y Sociedad (ISSN 2173-125X), n. ${ }^{\circ}$ 14, noviembre de 2021, pp. 303-323. \\ https://doi.org/10.12795/HabitatySociedad.2021.i14.16
}

\section{Summary}

In Argentina, the housing policy model conceived and applied during the 1950s, 1960s and later, deepened by the National Housing Fund (FONAVI) in 1972, was based on the idea that mass production would favor the sustained development of the construction industry, making it possible to overcome the deficit and benefiting the economy as a whole.

This model was implemented in the same way in rural areas, and public housing policies have not tended to address rural areas with their own identity, nor have they taken into account the ways of life and habitation of this population. In this sense, this paper sets out to carry out a historical review of the public rural housing policies carried out in Tucumán from 1860 to 2018, analyzing the logics and processes that they promote.

The results show that, since the creation of the Provincial Institute of Housing and Urban Development (IPVDU) in 1969, the production of state housing continues to focus on works with urban characteristics, without differentiating towards the rural interior of the province. This excludes the lifestyles and ways of life of the target populations.

Key words

Public policies; Housing; Rurality; Tucumán

\section{Resumen}

En Argentina, el modelo de política habitacional concebido y aplicado durante los ' 50 y ' 60 , profundizado luego desde el Fondo Nacional de Vivienda (FONAVI) en 1972, se fundó en la idea de que la producción masiva favorecería al desarrollo sostenido de la industria de la construcción, permitiendo superar el déficit y beneficiando a la economía en su conjunto.

Este modelo se implementó de igual manera en los ámbitos rurales y las políticas públicas habitacionales no han tendido a abordar lo rural con una identidad propia, ni se han tenido en cuenta los modos de vida y habitar de esta población. En este sentido, este trabajo se plantea realizar un recorrido histórico por las políticas públicas de vivienda rural llevadas a cabo en Tucumán desde 1860 a 2018, analizando las lógicas y procesos que promueven.

Entre los resultados se observa que, a partir de la creación del Instituto Provincial de la Vivienda y Desarrollo Urbano (IPVDU) en 1969, la producción de vivienda estatal continúa focalizada en realizar obras con características urbanas, sin diferenciarse hacia el interior rural de la provincia. Esto excluye los modos de vida y de habitar de las poblaciones destinatarias.

Palabras clave

Políticas públicas; Vivienda; Ruralidad; Tucumán

1 Arquitecta por la Facultad de Arquitectura y Urbanismo de la UNT. Doctora en Ciencias Sociales (orientación geografía) por la Facultad de Filosofía y Letras de la UNT. Becaria posdoctoral del Consejo Nacional de Investigaciones Científicas y Técnicas (CONICET) con lugar de trabajo en el Instituto de Estudios para el Desarrollo Social (INDES), perteneciente a la FHCSyS/UNSE-CONICET. E-mail: la_garay@hotmail.com. ORCID: 0000-0003-4517-5093.

2 Arquitecta por la Facultad de Arquitectura y Urbanismo de la UNT. Especialista Internacional en Ordenación del Territorio y Medio Ambiente, UNT, Universidad Politécnica de Valencia, España. Doctora en Urbanismo por la Universidad Politécnica de Valencia, España. Profesora Titular con dedicación exclusiva en la cátedra Teoría de la Arquitectura y directora del Centro de Estudios del Territorio y el Hábitat popular de la Facultad de Arquitectura y Urbanismo de la UNT. E-mail: claugolo@gmail.com. ORCID: 00000002-0575-9388. 


\section{Caracterización del problema}

La cuestión habitacional en América Latina es uno de los factores de mayor incidencia en la determinación de la pobreza y desde ya hace varias décadas, los indicadores habitacionales no han variado sustancialmente, y los problemas estructurales, de orden más cualitativo e integral, persisten (Gargantini, 2020a). En la Argentina, el modelo de política habitacional concebido y aplicado durante los cincuenta y los sesenta, profundizado luego desde el Fondo Nacional de Vivienda (FONAVI) en 1972, se fundó en la idea de que la producción masiva favorecería al desarrollo sostenido de la industria de la construcción, permitiendo superar el déficit y beneficiando a la economía en su conjunto (Cuenya, 1997), pero sin realizar políticas diferenciadas de acuerdo con las necesidades de los hogares. Algunas de las tendencias crónicas de las actuaciones de este campo son: la utilización del sistema "llave en mano" a través de la multiplicación de prototipos estándar que no responden a los modos de vivir, de habitar ni a la composición familiar; la poca o nula consideración de otros componentes asociados a la vivienda, como la localización espacial y el acceso al equipamiento social. Además, en estas tendencias no se tienen en cuenta variables como la pertenencia y la identidad de la comunidad; y producen inequidad social y territorial, la cual se evidencia en la relación entre las exigencias para la postulación y las contrapartes/obligaciones requeridas posteriormente. Sumado a esto, los gobiernos provinciales de la región priorizaron en sus políticas públicas sociales la atención de la población principalmente asentada en las áreas urbanas, profundizando el proceso de migración rural-urbana.

Los ámbitos rurales han sido considerados históricamente como espacios de producción de la materia prima y se caracterizan por la concentración de la tierra, la expansión del modelo agroindustrial y los modos de producción altamente intensivos, lo que profundiza la problemática de falta de acceso al hábitat digno de las comunidades indígenas, campesinos/as y pobladores/as rurales (Cejas, 2020). Las políticas públicas habitacionales que se implementan en estos ámbitos, también se sostienen desde una perspectiva centrada en el plano material y mercantilista, fomentado la urbanización, la consolidación de pueblos rurales y la transformación de las prácticas culturales como consecuencia de experiencias de relocalización, procesos que se podrían definir como "no esperados" (Quevedo, 2014).

La implementación de este modelo, "subestima el potencial de los lazos comunitarios y los saberes de las comunidades para acentuar su atención en las carencias materiales" (Cejas, 2020, pp. 10-11), las que se vinculan con la proliferación de enfermedades. Este argumento fue y es utilizado como idea fuerza en el discurso del desarrollo que sustenta las políticas habitacionales. La vivienda rancho, la cual es parte de la identidad de las comunidades del Noroeste Argentino, ha sido y es considerada una vivienda precaria por su vinculación a la enfermedad de Chagas, generada por la picadura de la vinchuca, que se aloja en los techos de paja y en las grietas del adobe. Sin embargo, el rancho en sí mismo no refleja a priori malas condiciones de vida para el hogar rural ya que "la vinchuca (vector de la enfermedad) puede anidar en cualquier espacio que le brinde cobijo, independientemente de sus materiales" (Cejas, 2020, pp. 12-13) por lo que esto se resolvería prestándole atención a las terminaciones y encuentros constructivos, permitiendo de esta manera rescatar su valor cultural. 
La provincia de Tucumán tiene 80955 viviendas rurales en todo su territorio, representando al 19,5\% de su población total (CNP, 2010). Además, en 2010 había 6448 hogares en condiciones de hacinamiento $^{3}(9,4 \%)$, el $31,5 \%$ de hogares con régimen de tenencia precario ${ }^{4}$ y el $32 \%$ tiene procedencia de agua para beber crítica $^{5}$ (Krapovickas y Garay, 2017).

Este trabajo pretende realizar un recorrido histórico por las políticas públicas de vivienda rural llevadas a cabo en Tucumán desde 1860 a 2018, analizando las lógicas y procesos que promueven. Para esto, se realiza una crono-secuencia ${ }^{6}$ en la cual se contextualizan los principales cambios socioeconómicos y políticos que impactan en la realidad tucumana y las políticas públicas de vivienda. La misma se realiza en los siguientes períodos: primeras intervenciones higienistas (1860-1880), la creación del Instituto Provincial de Vivienda y Desarrollo Urbano ${ }^{7}$ (en adelante IPVDU) y las políticas de reubicación rural (1960-1990), la liberalización de las políticas de vivienda (1990-2001) y el giro de las últimas décadas (2001-en adelante). Se responderán las siguientes preguntas: ¿Cuáles fueron los cambios socio-económicos y políticos más significativos que han impactado en el territorio provincial? ¿Qué políticas públicas de vivienda se han implementado en las áreas rurales de la provincia a lo largo de los períodos? ¿Qué procesos favorecen las mismas? Cabe aclarar que los alcances de esta investigación no permiten generar un conocimiento total de las políticas públicas habitacionales a lo largo de la historia, pero el relevamiento de algunas de ellas, que se presentan en este trabajo, permiten acercarse cualitativamente a los efectos de estos programas en las comunidades.

\section{Aproximaciones teóricas y metodológicas}

"Las políticas públicas son proyectos y actividades que un Estado diseña y gestiona a través de un gobierno y una administración pública a los fines de satisfacer necesidades de una sociedad" (Graglia, 2004, pp. 1920). Toda política pública constituye el conjunto de tomas de posición, por acción u omisión, de diferentes agencias e instancias del aparato estatal que expresan una determinada modalidad de intervención del Estado, en relación con una cuestión que despierta la atención, interés o movilización de actores de la sociedad civil (Oszlak y O`Donnell, 2007). "De dicha intervención puede inferirse una cierta direccionalidad, una determinada orientación normativa, que previsiblemente afectará el futuro curso del proceso social hasta entonces desarrollado en torno a la cuestión" (ob. cit., p. 565).

Los procesos habitacionales se generan en el marco de un sistema social, político y económico determinado, por lo que la explicación de las necesidades, problemas y procesos habitacionales no pueden encontrarse solo en el mismo sector de la vivienda, sino en la estructura social con sus respectivas relaciones de poder, condicionadas por la misma acción del Estado (Gargantini, 2012). Así, la política de vivienda se concibe como el conjunto de decisiones y acciones (directas e indirectas) del estado en materia habitacional, según el mandato que ha recibido de la población, teniendo en cuenta las diferencias existentes en relación con el poder y las características y funcionamiento del sistema político, y en busca de resoluciones adecuadas a las necesidades y problemas existentes (Gargantini, 2012). Gargantini (2020b) identifica dos tipos de modelos de gestión ${ }^{8}$ que parecen convivir en los ám-
3 El hacinamiento se define de acuerdo a los parámetros establecidos por el

INDEC, a partir de la convivencia de tres o más personas por cuarto.

4 Las categorías del INDEC (2010) que definen el régimen de tenencia crítico de la vivienda son: propietario solo de la vivienda, inquilino, ocupante por préstamo, ocupante por trabajo y otra situación (Krapovickas y Garay, 2017).

5 Las categorías del INDEC (2010) que definen la procedencia de agua para beber crítica son: pozo, transporte por cisterna y agua de lluvia, río, canal, arroyo o acequia (Krapovickas y Garay, 2017).

$6 \quad$ Si bien este recorte no es el recorte clásico llevado a cabo por diversos autores (Osatinsky y Longhi, 2017; Yujnovsky, 1971; entre otros), se fundamenta en los grandes cambios históricos que impactaron en la provincia y que tuvieron influencia en los medios rurales analizados en los estudios de caso de la tesis doctoral de una de las autoras (Garay, 2018).

7 Es el organismo del Estado que se encuentra facultado para elaborar la política, programación y ejecución de viviendas, ordenamiento y desarrollo de los centros urbanos, conforme a las atribuciones otorgadas por la Ley $\mathrm{N}^{\circ} 3793$. Con este fin, debe instrumentar y armonizar los recursos disponibles y potenciales, tanto económicas como tecnológicas a fin de mejorar las condiciones de alojamiento de las familias, especialmente las de menores recursos y que las viviendas contribuyan, por su emplazamiento y equipamiento, al bienestar de la comunidad, buscando el mejor y más racional uso de la tierra. En este sentido, propende a la formación, estabilidad y permanencia social del grupo familiar, integrándolo a la comunidad mediante la promoción y educación relacionada con la vivienda. 8 Un modelo de gestión se define como: "la estructura integral de abordaje al problema que se intenta resolver: conceptual, institucional y políticas, con sus definiciones de actores, roles, interrelaciones, fuentes y circuitos de flujo de recursos [...] es la guía o instructivo para el diseño de la planificación de las diferentes operaciones posibles que aseguren que la ejecución de los mismos va a responder a los propósitos y a la concepción de la forma de actuar que se posee" (Pelli, 2000, citado por Garantini, 2020b, p. 2). 
bitos locales: el modelo tradicional que responde a las líneas de acción históricamente implementadas y el modelo de gestión integral y actoral que es considerada una nueva forma de acción en materia sociohabitacional por la incorporación y coexistencia de abordajes innovadores.

La revisión histórica de las políticas públicas habitacionales supone relacionarlas no solo con la concepción de vivienda que adoptaron los agentes responsables de las mismas, sino también con los importantes cambios que se han producido en el modo de acumulación capitalista y las consecuentes transformaciones que ha sufrido el Estado a lo largo de los años. Las soluciones y respuestas en materia habitacional que vienen implementándose desde el Estado han dado prioridad al modelo de gestión tradicional, produciendo vivienda completa (llave en mano). Las mismas se gestionan mediante los IPVDU y son construidas por constructoras privadas, con el apoyo en muchos casos de los Gobiernos Municipales. Esta concepción taylorista asociada a la industrialización de la construcción de principios del siglo xx, considera que existe un usuario universal que responde a las mismas necesidades, y que requiere, por lo tanto, soluciones universales abonadas por propuestas como las de la Baucentrum, los estudios de Alexander Klein, las propuestas de Neufert hasta los prototipos de Le Corbusier basados en su Modulor. Nada más alejado que la necesaria contextualización y adaptación de soluciones apropiadas y apropiables las demandadas por el hábitat rural.

La cuestión de la vivienda para el sector rural plantea problemas de diversa índole, que no han sido abordados en forma sistemática y, en consecuencia, tampoco han originado definiciones de políticas públicas habitacionales acordes para el sector (cfr. Rodulfo et al., 2000, p. 133). Sánchez Quintanar y Jiménez Rosas (2010) plantean que para el estudio de la lógica de la vivienda rural (VR) es necesario conocer las actividades a las que se dedica la familia y los ecosistemas en donde se ejecutan y las relaciones intrafamiliares y externas con las cuales se forman las redes sociales de las comunidades, así como la cultura que rige sus comportamientos familiares y sociales. La vivienda representa un componente fundamental en tanto entidad que se constituye en un elemento de inserción e identificación social (Krapovickas y Garay, 2017). La vivienda es ámbito de protección y resguardo físico de hogares, familias y grupos, tanto como espacio social de las relaciones entre sus integrantes (Lucero et al., 2005).

"El espacio socialmente producido condicionaría la (re)producción de las desigualdades al influir no solo en la calidad y la ubicación de la vivienda y su entorno, sino también en las oportunidades relacionadas con la educación, la salud y el trabajo, entre otras dimensiones de la vida social" (Segura, 2020, p. 90). Es por esto por lo que para la implementación de políticas públicas es necesario tener en cuenta la accesibilidad, los bienes y servicios, y la distancia adecuada a las tierras de cultivo; es decir, no se puede implementar una política pública habitacional, sin tener en cuenta una política integral del hábitat rural, la cual es definida como "el conjunto de manifestaciones materiales e inmateriales que dan cobijo a las actividades humanas de salud, educación, trabajo, vivienda y recreación, en entornos de ruralidad, caracterizado por ser dinámico ya que es el resultado de las intervenciones de los pobladores, el Estado y el mercado, las cuales responden a pautas culturales y sociales que tienen diferentes lógicas" (Garay, 2019, p. 6). 
En este sentido, este trabajo se plantea analizar las políticas de vivienda rural llevadas a cabo en Tucumán, mediante una metodología mixta (cuantitativa y cualitativa). Las técnicas abordadas son:

- Análisis de datos estadísticos a partir del Censo Nacional de Población, Hogares y Viviendas 2010: se realizaron análisis espaciales de distribución de la población rural, de las viviendas y de las políticas públicas implementadas.

- Análisis de documentos: se realizó una reconstrucción histórica acerca de la vivienda rural y las políticas públicas implementadas en la provincia de Tucumán desde las primeras intervenciones hasta la actualidad, a partir de documentos históricos y publicaciones de académicos de la provincia.

- Entrevistas abiertas: se realizaron a pobladores/as rurales de Taco Ralo y Gobernador Piedrabuena, personal del IPVDU y de la Secretaría de Agricultura Familiar (SAF) que formaron parte del Programa Social Agropecuario (en adelante PSA). Las entrevistas y parte del trabajo presentado forman parte de la tesis de la Dra. Ana Garay (2018), dirigida por la Dra. Claudia Gómez López y financiada por una beca doctoral del Consejo Nacional de Investigaciones Científicas y Técnicas (CONICET) durante el período 2013-2018.

\section{Breve recorrido de las políticas públicas habitacionales en el ámbito rural tucumano (1869-2018)}

\section{Las primeras intervenciones higienistas (1860-1960)}

Hacia 1852 la estructura productiva de la provincia de Tucumán era altamente diversificada, ocupando la agricultura el 32,6\%, la ganadería el 29,6\% y la industria el 37,8\% del ingreso total, de los cuales se exportaba el 34, el 44 y el 70\% respectivamente (Cfr. Gómez López et al., 1994, p. 20). En el desarrollo del sector manufacturero se destacaban las fábricas de destilación, curtiembres, zapaterías, carpinterías, destacándose a partir de 1950 la producción de azúcar y aguardiente (Romero, 2017).

La presencia de un vasto campesinado caracterizaba a la provincia, donde la familia era una unidad de producción que prácticamente se autoabastecía presentando un carácter multi-funcional. El campesino poseía un pedazo de tierra para trabajar (Halperin Donghi, 1972, citado por Bolsi, 2000) y aun cuando eran mayoritariamente ocupaciones de hecho (lo que denota un reparto no homogéneo de la tierra) esto permitió garantizar ciertas condiciones de vida básicas de la población rural (López de Albornoz, 1998), la cual representaba en 1869 el 80,1\% (CNP, 1869, en Ortiz de D'Arterio, 2017b).

Las casas de Tucumán en el año 1869 se destacaban por estar realizadas mayormente con adobe y paja, representando al 89,6\% del total de las viviendas. A su vez, se encontraban otros materiales entre los que observan: piedra o ladrillo con techo de azotea $(2,7 \%)$, piedra o ladrillo con techo de teja, fierro o zinc $(7,5 \%)$ y casas de madera $(0,2 \%)$ (Osatinsky, 2017). Entre las preocupaciones del discurso higienista se encontraba la mejora de las viviendas, observando que debían erradicarse las construcciones con adobe propias de las poblaciones rurales, considerándose necesaria la construcción de la vivienda con "materia- 
les" como el hormigón, ladrillo hueco, mosaicos, baldosas (Mendióroz, 1942). A su vez, se plantea que, para evitar el ingreso del mosquito, se debe diseñar la vivienda con una sola entrada y el uso de mallas metálicas en ventanas, justificándose en los siguientes fragmentos:

El paludismo domina en casi la totalidad de la provincia [...] constituye, sin duda, el más serio peligro para la salud de la población rural que, desgraciadamente con ello llegó a sufrir hasta en su desarrollo físico [...] los pobladores de esta riquísima región llevan, en materia de habitación, una vida paupérrima. El otorgamiento de casas humanas a los campesinos redundará, como acto de justicia, en la elevación de su condición social con todas sus benéficas consecuencias de orden moral y material (Mendióroz, 1942, pp. 35-36).

En 1895, las viviendas continuaban siendo mayormente con adobe y paja, pero luego de las primeras intervenciones higienistas ya se visualizaba una pequeña disminución respecto al período anterior, representando al 73,9\% del total. A su vez, se encontraban otros materiales: piedra o ladrillo con techo de azotea (4,3\%), piedra o ladrillo con techo de teja, fierro o zinc $(19,8 \%)$, casas de madera (1\%) y casas de fierro $(1,1 \%)$ (Osatinsky, 2017).

Esta situación también se vio influenciada por la modernización industrial y la urbanización que se dio con la llegada del Ferrocarril Central Norte en 1876. A partir de este momento, se consolidó la industria azucarera como la producción de mayor importancia en la provincia de Tucumán ocupando una porción importante en el territorio, particularmente en el pedemonte. Esto modificó la configuración del territorio provincial, los modos de vivir y de habitar de la población, conformándose aproximadamente el $90 \%$ de las ciudades existentes, por la consolidación de pueblos preexistentes o porque surgieron como escala de transporte del ferrocarril (Gómez López et al., 1994). En 1960 la población rural había disminuido considerablemente al 45,60\% (CNP, 1960, en Ortiz de D'Arterio, 2017b).

Ortiz Bergia y Salomón (2017) plantean que el modelo dicotómico (campo-ciudad) explicativo del funcionamiento del espacio rural se dio desde el siglo xIx hasta la segunda guerra mundial. A partir de la posguerra, comenzó a cobrar fuerza la idea de conexión entre el mundo rural y el urbano, haciendo referencia a que los procesos rurales eran una continuidad de los procesos urbanos. El estudio sobre las condiciones de reproducción en el mundo rural en la primera mitad del siglo xx ha propiciado menor atención que las temáticas agrarias, aplicando tanto a la situación de la vivienda como a las formas de acceso a la salud, la alimentación, los servicios públicos, el ocio y la educación general, prolongándose durante décadas los niveles de analfabetismo, las dificultades para acceder a prestaciones médicas, la mala calidad de los alimentos, la desprotección de la infancia, las condiciones de inseguridad en los campos y la precariedad de las comunicaciones (Ortiz Bergia y Salomón, 2017).

La creación del IPVDU y las políticas de reubicación rural (1960-1990)

En 1966, el problema azucarero y las perturbaciones gremiales fueron usados por la autodenominada "Revolución Argentina" como argumentos para interrumpir el gobierno constitucional (Romero y Ragone, 2017). En este contexto, el 9 de julio de 1966 se impuso una 
limitación general a la producción de azúcar del $70 \%$ respecto a lo producido el año anterior y se establecieron estrictos cupos, eliminando del sistema a todas aquellas explotaciones menores a tres hectáreas. A ello se sumó el cierre, entre 1966 y 1968, de 11 de los 27 ingenios de la provincia, la prohibición de instalar nuevas fábricas azucareras o de ampliar la capacidad productiva de las ya existentes y la eliminación del crédito estatal para los emprendimientos agrícolas o industriales vinculados al azúcar. De las más de 18000 explotaciones registradas al promediar la década de 1960, alrededor de 17341 estaban a cargo de campesinos minifundistas; en tanto que al finalizar el año 1980 el número de explotaciones se había reducido a 11496 y de estas solo 6912 estaban en manos de campesinos (Paolasso, 2004). Esto conllevó una profunda crisis que ponía en evidencia las limitaciones propias de la dependencia hacia la monoproducción, observándose a partir de esto un claro retroceso en las condiciones de vida (Longhi et al., 2013).

El profundo impacto que tuvo esto sobre la población tucumana, especialmente en las zonas azucareras, se puede observar en la disminución de la población tanto en términos relativos como absolutos (Paolasso, 2004), fundamentalmente de los centros menores, entre 500 y 2000 habitantes (Gómez López et al., 1994). En este contexto, en el período entre 1960 y 1970 se observa un retroceso de los valores de densidad de la franja central, con la emigración de aproximadamente 200000 tucumanos, que significa el 25\% de la población de 1970 (ob. cit.). La emigración de la población hacia otras áreas del país (Capital Federal, Gran Buenos Aires, Salta, Santiago del Estero y Santa Fe) se agudizó, al mismo tiempo que aumentaron los flujos de trabajadores por temporadas y con retorno al lugar de residencia. Entre 1960 y 1991, se profundiza la tendencia a la urbanización, pasando de un $54,4 \%$ de población urbana a un 76,7\% (CON 1960 y 1991, en Ortiz de D'Arterio, 2017a).

En 1969 se concretó la creación del IPVDU y se reglamentó por la Ley Provincial 3619 el 06/04/1972. Como en el resto del país, el accionar del IPVDU estuvo focalizado a actuaciones de índole urbana (conjuntos de viviendas y equipamientos de carácter urbano), razón por la cual el Área Metropolitana de Tucumán (AMeT) se destaca por concentrar la mayor parte de las viviendas realizadas. Hacia el interior rural de la provincia, el IPVDU realizó numerosas actuaciones no muy diferenciadas de las ejecutadas en el AMeT y se trata en general de conjuntos de viviendas de tamaño mediano o chico (250 unidades a 50 unidades), resueltos sobre la tipología de vivienda individual en lote propio. El marco normativo provincial respecto al diseño de estos conjuntos viene definido por la Ley Provincial de Loteos $\mathrm{N}^{\circ} 5380$ del año 1982, estableciendo como lote mínimo una parcela de $250 \mathrm{~m}^{2}$ y 10 metros de frente mínimo.

A través de esta institución, en 1976 se llevó a cabo una de las medidas para reprimir la resistencia rural mediante la creación de un Organismo ad hoc de Reubicación Rural mediante la ley n. ${ }^{\circ} 4530^{9}$ que declaraba de interés provincial la necesidad de ordenar los poblados correspondientes a las localidades de Caspinchango, Los Sosa, Yacuchina y Colonia 5. El mismo estaba en dependencia directa del gobernador Bussi y debía hacerse cargo del estudio, proyecto y ejecución de las obras necesarias para el reordenamiento. En consecuencia, se crearon cuatro pueblos: Teniente Rodolfo Hernán Berdina, Soldado Ismael Maldonado, Capitán Héctor Cáceres y Sargento Miguel Arturo Moya, los cuales se localizan en una línea imaginaria paralela a la vieja traza de la ruta nacional 38 (Figura 1), de norte a sur, al oeste de la circunscripción de Monteros. La construcción de estos pueblos durante
9 Entre los considerados de dicha ley, se menciona: "El estado actual de la vivienda rural en la Zona de Operaciones constituye fundamento cierto de la prédica subversiva que encuentra en las condiciones infrahumanas en que se desenvuelven ciertos sectores, juicios valederos para su acción disociadora; por otra parte, la dispersión actual que ofrece el poblador rural en la zona afectada, dificulta el control por parte de las fuerzas de seguridad; y que la reubicación de las poblaciones, brindándoles todos los servicios que ofrece y requiere la vida moderna, aun en índices de mínimo confort, comporta la forma más directa y eficaz de erradicar las causas que explota la subversión, a la par que ofrece las mayores perspectivas para su organización, control y seguridad". 
el proceso militar refleja la falta total de adecuación de estos prototipos al ámbito rural, lo que estuvo en consonancia con los objetivos de la dictadura en tanto homogeneización de la población, eliminación de la cultura de los ámbitos rurales y la generación de condiciones estandarizadas de habitabilidad, tendencia que se fue consolidando hasta nuestros días. En definitiva, el rol sustancial de estas políticas de vivienda rurales fue controlar y dominar el territorio rural "urbanizado" a través de la creación de nuevos pueblos rurales.

La estructura espacial de estos poblados mantuvo un diseño geométrico plasmado en el trazado de su amanzanado, respondiendo a un damero con manzanas rectangulares dispuestas geométricamente, con 70 viviendas y disponía de una plaza central (Rivas, Aguilar y Ale, 2016). Asimismo, estas autoras afirman que estos pueblos respondían a los lineamientos que el desarrollo de la industria azucarera había generado durante todo el siglo xx en la llanura central y en el pedemonte de la provincia, lo cual le permitió mantener el funcionamiento de tres ingenios azucareros y un paisaje rural con parcelas de caña de azúcar, cargaderos, fincas con galpones y equipamientos para la zafra. La realización de estos pueblos refleja, como el resto de las operatorias realizadas, la falta total de adecuación de los prototipos utilizados (los mismos que en conjuntos urbanos) y resulta, en síntesis, la mera repetición de soluciones estereotipadas para la ciudad en terrenos rurales.

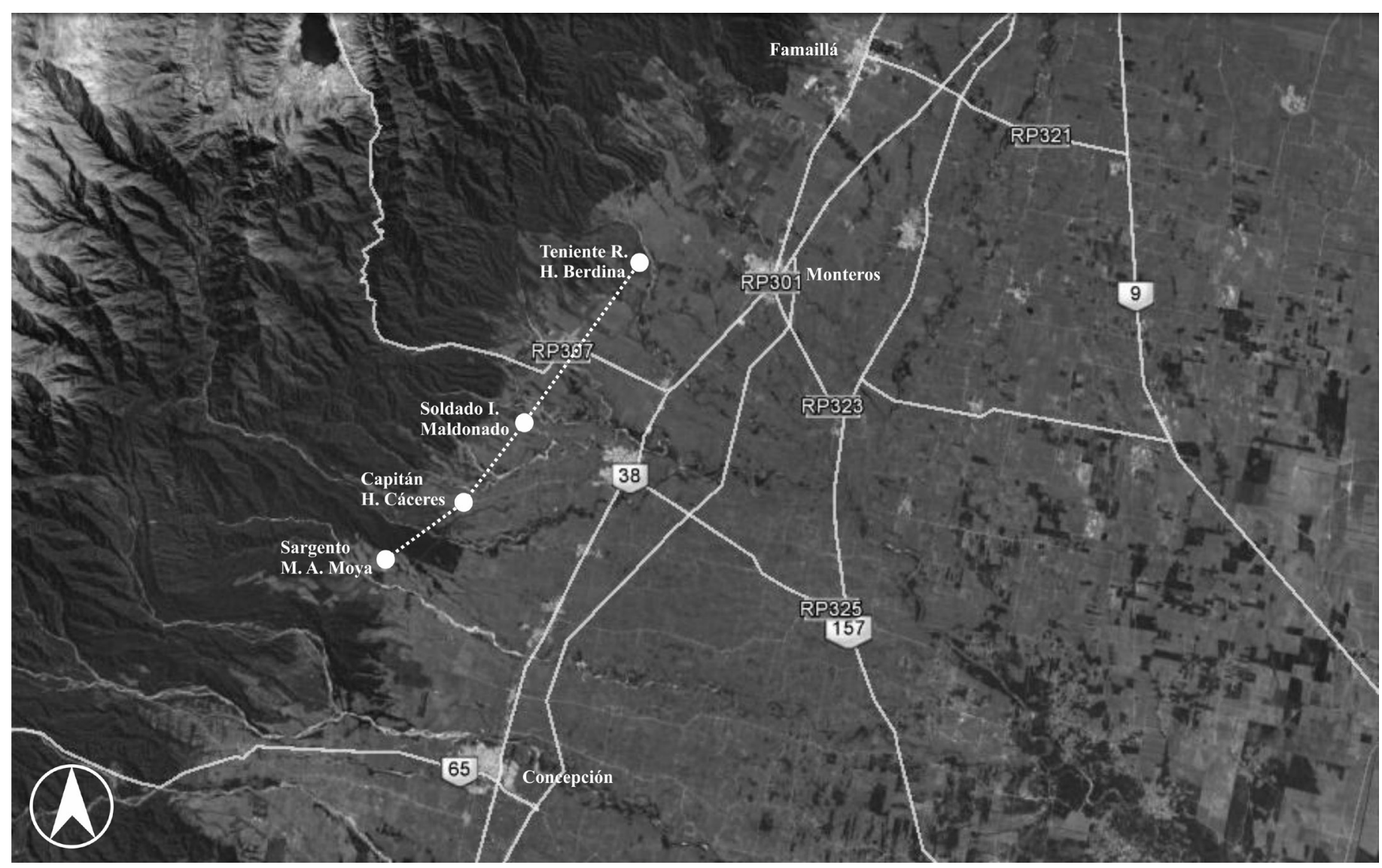

Figura 1: Pueblos nacidos en el marco de la dictadura militar de 1976. Fuente: Garay, 2018
Respecto a provisión de servicios en las viviendas, entre 1960 y 1980 , se redujeron los porcentajes de viviendas sin cañerías de agua dentro de la vivienda (de $64,1 \%$ a $50,5 \%$ ), de viviendas sin retrete con descarga de agua (de $66,1 \%$ a $46,3 \%$ ) y de viviendas sin electricidad $(52,3 \%$ a 27,5\% ) (Osatinsky, 2017), siendo esta última variable la que mayores mejorías mostró (Tabla 1). 


\begin{tabular}{|c|c|c|c|c|c|c|}
\hline & \multicolumn{2}{|l|}{$\begin{array}{l}\text { \% de viviendas sin } \\
\text { cañerías de agua } \\
\text { dentro de la misma }\end{array}$} & \multicolumn{2}{|l|}{$\begin{array}{l}\text { \% de viviendas sin } \\
\text { retrete con descarga } \\
\text { de agua }\end{array}$} & \multicolumn{2}{|l|}{$\begin{array}{l}\text { \% de viviendas sin } \\
\text { electricidad }\end{array}$} \\
\hline Año & 1960 & 1980 & 1960 & 1980 & 1960 & 1980 \\
\hline$\%$ & 64,1 & 50,5 & 6,1 & 6,3 & 52,3 & 27,5 \\
\hline
\end{tabular}

Tabla 1: Características de la vivienda según indicadores seleccionados. Tucumán (1960 y 1980). Fuente: Osatinsky, 2017

\section{La liberalización de las políticas de vivienda}

A partir de los noventa, una de las políticas más notables dirigidas al sector rural es el Decreto de Desregulación de noviembre de 1991, el cual incluía la eliminación de todas las entidades reguladoras de la producción agropecuaria que habían sido creadas desde 1930: la Junta Nacional de Granos, la Junta Nacional de Carnes, la Dirección Nacional del Azúcar. A partir de entonces, el sector agropecuario argentino se mantiene en condiciones de desregulación total (Giarracca y Teubal, 2006). Por otro lado, a partir de 1996 comenzó la implantación de la semilla transgénica de la soja RR que se combina con la denominada siembra directa y la utilización del glifosato, el agroquímico exclusivo aplicable a aquella implantación. Se trata de una producción que tiene dos consecuencias importantes para el perfil del agro argentino: en primer lugar, contribuye significativamente a la desaparición de una serie de explotaciones agropecuarias; y, en segundo lugar, se trata de una producción orientada casi exclusivamente hacia la exportación que sustituye en gran medida la producción de alimentos básicos orientados hacia la demanda del sector interno (ob. cit.).

Estas transformaciones generan reconfiguraciones en la relación entre población rural y territorio, produciendo un quiebre con el modelo de desarrollo rural familiar, proceso que terminaría en lo que algunos autores denominan agricultura sin agricultores (Giarracca y Teubal, 2006). Esto incluye la desaparición de un buen número de productores en las áreas cañeras, sobre todo de los más pequeños y un continuo proceso de concentración de la tierra con grandes capacidades para los agronegocios generando mayor acumulación del capital y la mayor importancia de los nuevos cultivos.

Asimismo, en este período se produce un desplazamiento de competencias del área nacional a los IPVDUs y a los municipios. Se reestructuraron el Banco Hipotecario Nacional (BHN) ${ }^{10}$ y el Fondo Nacional de Vivienda (FONAVI), ${ }^{11}$ promoviendo al sector privado y dejando en manos del mercado a los sectores sociales antes subsidiados directamente por el Estado. Por otro lado, en este período se añaden dos líneas de acción directa en el marco del "gasto social"12 (Gargantini, 2012). Este período de política neoliberal se caracteriza por la poca construcción de viviendas públicas (mayormente destinadas a la clase media y urbana) y por la privatización.

En Tucumán, entre 1996 y 1997, durante el gobierno democrático de Bussi, se implementó el programa de vivienda rural llevado a cabo por el PSA ${ }^{13}$ con fondos del Banco Interamericano de Desarrollo, mediante el cual se construyeron 50 soluciones habitacionales de iguales características que se destinaron a pequeños productores de caña, tabaco y hortalizas. Se realizó mediante un convenio con la Facultad de Ciencias Exactas y con la dirección técnica de la Facultad de Ingeniería. Este programa se construía con un modelo tipo que contenía dos dormitorios, un baño y cocina, para lo cual el Estado ponía $\$ 5000$ y los
10 El BHN fue transformado primeramente en Banco Mayorista y luego en Sociedad Anónima sujeta a privatización, la que se consolidó en 1997.

11 El FONAVI, por su parte, sufrió el cambio del origen de los recursos (se eliminó el impuesto al trabajo, reduciendo los costos laborales de las empresas), la descentralización de la administración de los recursos (objetivo ampliamente buscado por los gobiernos provinciales), la diversificación de las operatorias y el establecimiento del Sistema Federal de Vivienda (Cfr. Gargantini, 2012, p. 17) 12 Por una parte, se incorporan acciones llevadas a cabo a partir de financiamientos de la banca internacional con destinos específicos (Programa Mejoramiento de Barrios-PROMEBA), Programa 17 , etc.) y por otra parte se implementa el denominado "Plan Arraigo" de la Comisión Nacional de Tierras Fiscales de la Presidencia de la Nación, destinado a la regularización de tierras (Cfr. Gargantini, 2012, pp. 19-20).

13 Entrevista a técnico de la Secretaría de Agricultura Familiar (año 2015). 
productores autoconstruían con previas capacitaciones en albañilería e instalaciones.

En consonancia con el contexto de avance de los monocultivos, en la localidad de Piedrabuena se construyó un barrio de viviendas sobre la ex ruta 34 que corresponden a dos operatorias diferentes llevadas a cabo por el IPVDU, con personal de la Comuna, pero sin involucrar a las familias destinatarias en el proceso de diseño y de construcción (Garay, 2018). El proyecto se emplaza alrededor de una plaza pública (Figura 2). Las primeras 24 viviendas pertenecen al barrio 102 viviendas, fueron construidas aproximadamente a fines de 1980 y cuentan con tres dormitorios, baño y cocina-comedor. Las segundas se construyeron a principios del 2000 y son más pequeñas que las primeras, ya que cuentan con dos habitaciones, un baño y la cocina-comedor. Si bien ambos proyectos se construyeron con ladrillo y hormigón, el material de la cubierta fue en el primer caso, de tejas y en las segundas de chapa.

En todas las entrevistas surgen apreciaciones positivas sobre lo que este cambio significó en la vida de las familias, en cuanto a la mejora en sus condiciones de vida y habitar, principalmente relacionado con el acceso a servicios básicos y con la disminución del problema de la vinchuca. La mayoría de las personas entrevistadas, vivían en parajes cercanos a esta localidad, no tenían electricidad ni agua potable en sus lugares de origen, se utilizaba mecheros (trapos embebidos con gasoil) y se transportaba el agua desde Piedrabuena con carros. El hecho de tener agua por red o locales agrupados y nucleados son aspectos de la vivienda que los pobladores valoran positivamente en contraposición a las viviendas anteriores que tenían la cocina y el baño siempre afuera por cuestiones de higiene (uso de letrinas) o seguridad (cocinas a leña).

Sin embargo, la implementación de estos barrios tuvo como consecuencia la desterritorialización de la población que vivía dispersa en el territorio y la ruptura entre la relación dialéctica de la parcela productiva y la vivienda, reterritorializándose en estos barrios y modificando la relación con el "campo". Tal como lo resaltan en diversas entrevistas existe una nostalgia por la vida "de campo" que incluye la cría de sus animales, que las dimensiones de los lotes actuales no permiten realizar. "Aquí no podemos tener animales ni sembrar nada porque se molestan los vecinos y si entra a la finca, el finquero los mata porque ya es propiedad privada" (entrevista 05/07/17).
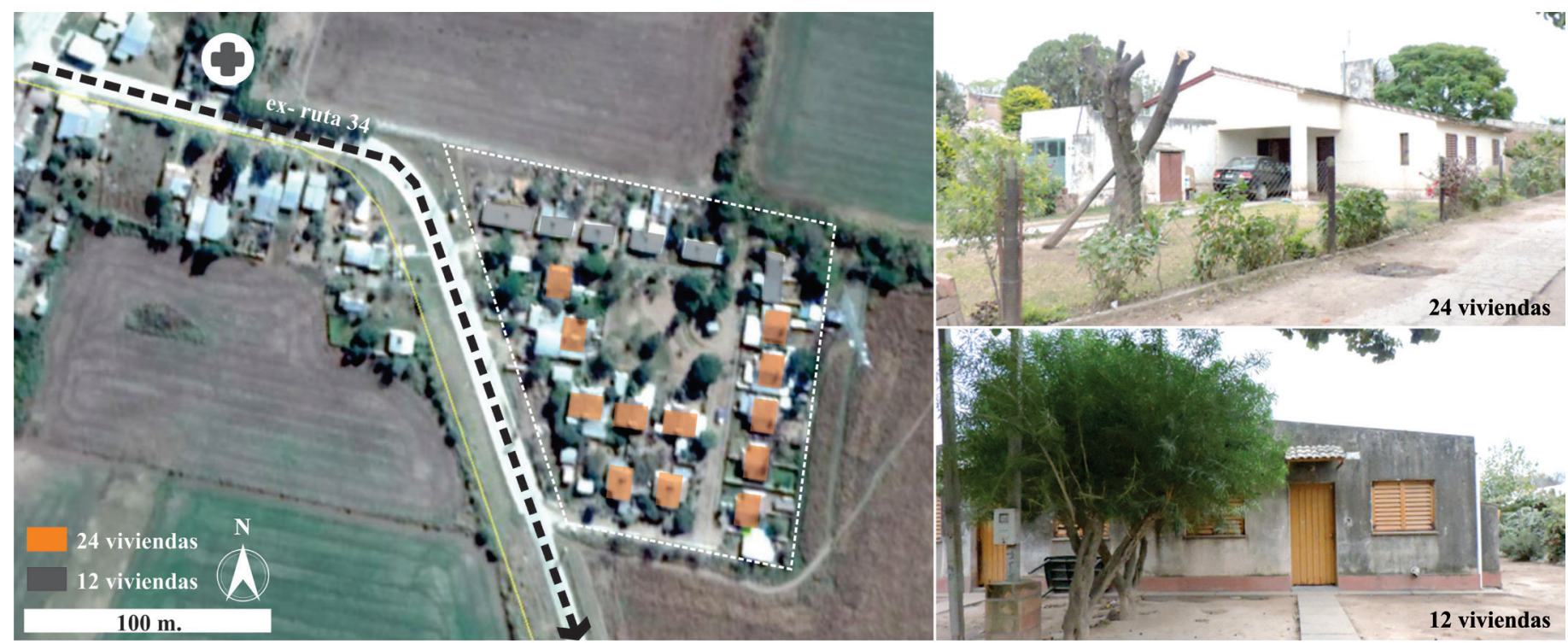


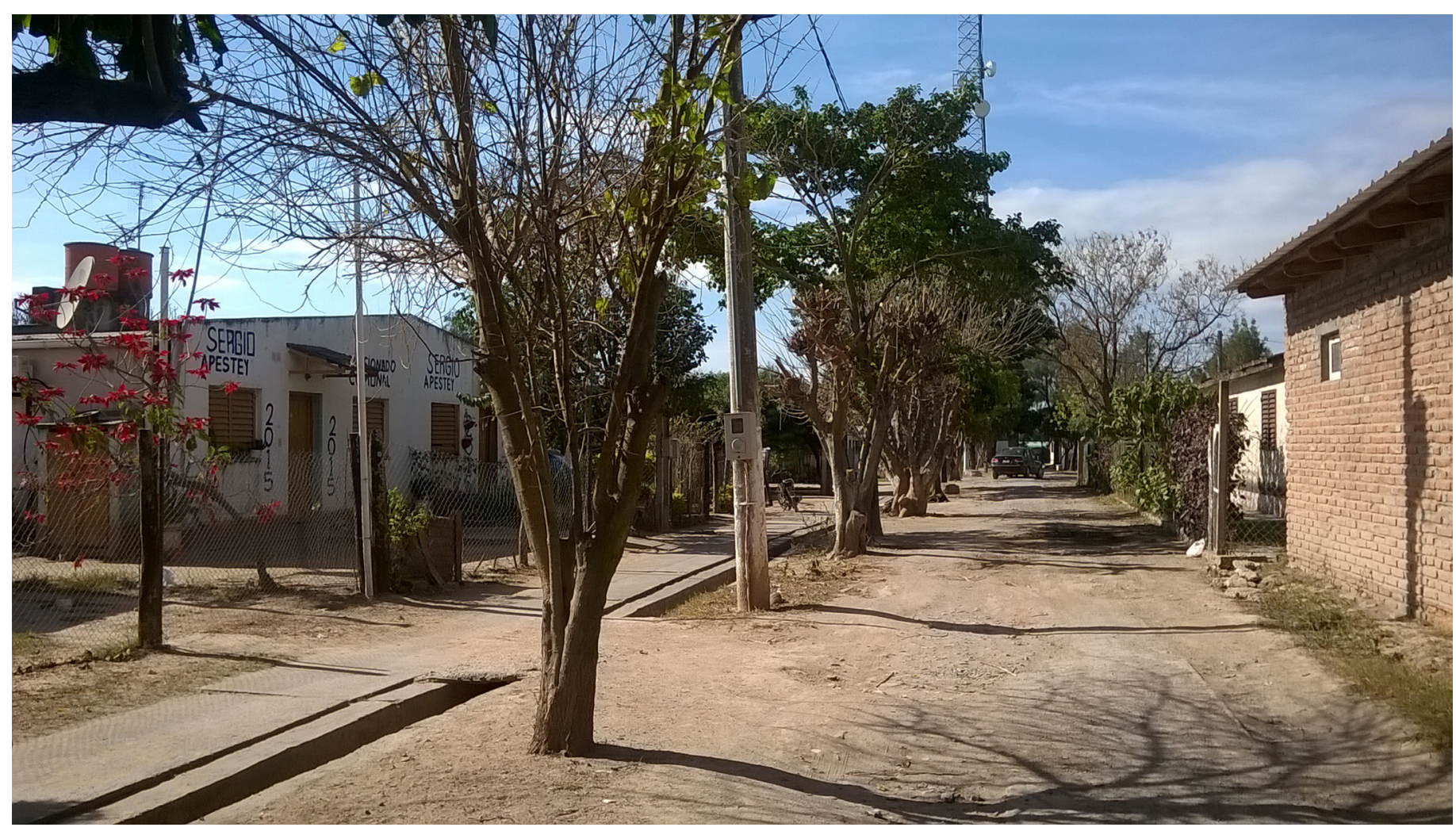

\section{El giro de las últimas décadas}

Las actividades productivas capital-intensivas profundizan las desigualdades socio- territoriales, observándose como evidencias claras de estos procesos en las áreas rurales del NOA: "la progresiva descampesinización de los territorios rurales (Paz, 2006), la emergencia y proliferación de villas miseria en los pueblos, la escasez de alternativas productivas viables, la presión sobre la tierra y la emigración rural (Bolsi, 2004)" (Krapovickas y Garay, 2017, p. 607). Tucumán presenta estas mismas características y según datos del último censo (CNP, 2010) la provincia mantiene un 19,5\%, representando a 281731 personas. Hacia el interior, los departamentos con menor porcentaje de ruralidad se encuentran en el aglomerado metropolitano (Tabla 2 y Figura 3): Capital (0\%), Yerba Buena $(3,94 \%)$ y Tafí Viejo $(14,46 \%)$. En el siguiente grupo (de 14 a 39\%) se encuentran los departamentos del área pedemontana, Cruz Alta (19,93\%), Río Chico (22,97\%), Lules $(23,36 \%)$, Chicligasta (27,58\%), Monteros (29,98\%), Famaillá $(33,63 \%)$ y Juan Bautista Alberdi $(39,05 \%)$. El tercer y cuarto grupo, están compuestos por aquellos que contienen mayor cantidad de población rural. El primero (de 39 a $68 \%$ ), contiene a los departamentos de Trancas $(56,86 \%)$, Graneros $(61,51 \%)$, La Cocha $(65,38 \%)$ y Leales $(68 \%$ ). El segundo (de 68 a $79 \%$ ) solo lo componen los departamentos de Simoca $(72,95 \%)$, Tafí del Valle $(77,21 \%)$ y Burruyacú $(79,37 \%)$ (Garay, 2018). Estos últimos departamentos se encuentran ocupando el norte de la provincia, en su sector montañoso mayoritariamente, mientras que Simoca y los del segundo grupo se encuentran fuera del área cañera pedemontana, actividad que estuvo directamente vinculada con el proceso de ocupación de la Provincia en el siglo XIX (Gómez López et al., 1994).
Figura 2: Barrio de Viviendas en Piedrabuena, Burruyacu, Tucumán. Fuente: Garay, 2018 


\begin{tabular}{|c|c|c|c|c|c|}
\hline Grupo & Departamento & $\%$ población rural & Total Viv. Rurales & Total Viviendas & $\%$ \\
\hline \multirow{3}{*}{ G1 (de 69 a $79 \%)$} & Burruyacú & 79,4 & 8420 & 10335 & 81,5 \\
\hline & Tafí del Valle & 77,2 & 6634 & 8517 & 77,9 \\
\hline & Simoca & 73,0 & 6425 & 8660 & 74,2 \\
\hline \multirow{4}{*}{ G2 (de 41 a $68 \%)$} & Leales & 68,0 & 10642 & 15209 & 70,0 \\
\hline & La Cocha & 65,4 & 3311 & 5043 & 65,7 \\
\hline & Graneros & 61,5 & 2448 & 4143 & 59,1 \\
\hline & Trancas & 56,9 & 3326 & 6889 & 48,3 \\
\hline \multirow{7}{*}{ G3 (de 16 a $40 \%$ ) } & Juan B. Alberdi & 39,1 & 3190 & 8261 & 38,6 \\
\hline & Famaillá & 33,6 & 2753 & 8124 & 33,9 \\
\hline & Monteros & 30,0 & 5277 & 17168 & 30,7 \\
\hline & Chicligasta & 27,6 & 5702 & 20605 & 27,7 \\
\hline & Lules & 23,4 & 3960 & 16869 & 23,5 \\
\hline & Río Chico & 23,0 & 3234 & 14733 & 22,0 \\
\hline & Cruz Alta & 19,9 & 9257 & 42951 & 21,6 \\
\hline \multirow{3}{*}{ G4 (de 0 a 15$)$} & Tafí Viejo & 14,5 & 5575 & 31491 & 17,7 \\
\hline & Yerba Buena & 3,9 & 801 & 19691 & 4,1 \\
\hline & Capital & 0,0 & 0 & 157351 & 0,0 \\
\hline \multicolumn{2}{|l|}{ Tucumán } & 19,5 & 80955 & 396040 & 20,4 \\
\hline
\end{tabular}

Tabla 2: Población rural (totales relativos) y viviendas rurales (totales absolutos y relativos). Fuente: CNP 2010, INDEC.
14 Mediante la ley Nacional $N^{\circ} 24.464$, se crea el Sistema Federal de Vivienda en 1995. Posteriormente, por Ley $\mathrm{N}^{\circ} 25570$, se establecen los acuerdos sobre Coparticipacion Federal de Impuestos, en el año 2002.
Con respecto a la cantidad de viviendas rurales de la provincia (Tabla 2), se observa que existen 396040 en la provincia (CNP, 2010). Los valores que se consignan en el cuadro a nivel departamental denotan que aquellos departamentos que contienen municipios o comunas rurales vinculadas total o parcialmente al AMeT son los que menores valores de vivienda rural poseen: Capital (San Miguel de Tucumán), Yerba Buena y Tafí Viejo (municipios homónimos), Cruz Alta (La Banda del Río Salí y Alderetes) y Lules (Comuna del Manantial).

Las políticas públicas habitacionales implementadas en las últimas décadas intentan superar la centralización del Estado respecto a las Provincias, ${ }^{14}$ pero las mismas fueron nuevamente subordinadas a partir del 2003 a la disponibilidad de recursos destinados a la Política Federal de Vivienda (PFV) por parte del Poder Ejecutivo Nacional (Rodulfo y Boselli, 2015). En el contexto provincial, a partir de 2003 se realizó una gran inversión en materia de vivienda dentro de la provincia. Los programas con los que se financian las obras están destinados a la dotación de infraestructura, a la construcción de vivienda nueva y a la mejora de vivienda según se detalla a continuación:

1) Programas para la dotación de infraestructura: Pro.me.ba; Pro. me.ba transición; Techo Digno; Programa Fiducidiario y Fondos Especiales.

2) Programas para la construcción de vivienda nueva: Reactivación I; Reactivación II; Recursos Propios, Solidaridad Habitacional; Plurianual; Programa de Integración; Techo Digno; FEDvillas y Pro.mat. 


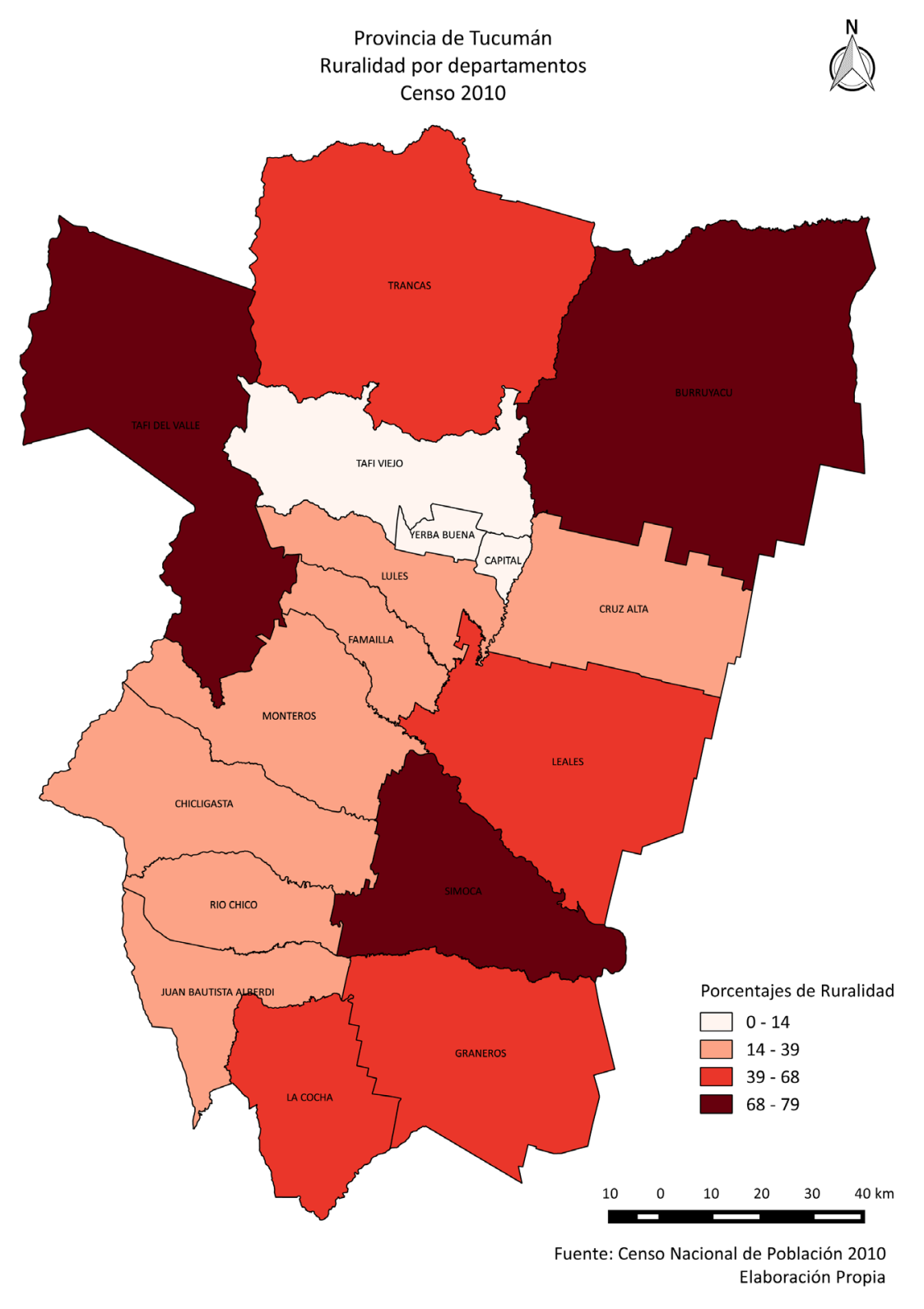

3) Programas de mejoramientos de viviendas existentes: Pro.mat; Complemento Pro.me.ba; PRO.Me.Vi; Emergencia Hídrica; Programa de Integración y Mejor Vivir y el Programa Federal de Vivienda y Mejoramiento del Hábitat de Pueblos Originarios y Rurales.

En el interior de la provincia el IPVDU ejecutó numerosos programas habitacionales y de mejora del hábitat. En los últimos 16 años (2003-2018) se consignan la construcción de 6000 viviendas y la realización de 14153 obras de mejora de vivienda en el interior de la provincia. ${ }^{15}$ En la Tabla 3 se presentan los resultados totales para la provincia diferenciando, en la parte inferior, los correspondientes a las áreas rurales antes mencionadas.

Del análisis realizado se contabiliza que solo el $26 \%$ de las viviendas construidas se realiza en el interior en áreas rurales o próximas, como así también el 32\% de las mejoras habitacionales realizadas en la provincia y los programas con los que se interviene son: Pro.me.ba I, II y Transición; Programa Federal de construcción de vivienda Techo Digno, Reactivación 1 y 2; Recursos propios; Solidaridad habitacional,
Figura 3: Ruralidad en la provincia de Tucumán por departamentos (2010). Fuente: Garay, 2018
15 No se consideran las obras realizadas en el AMeT, ni en ciudades intermedias del interior como Concepción, Alberdi o Monteros en sus áreas urbanas, puesto que no se trata de intervenciones en ámbitos rurales. 
Tabla 3: Total de obras ejecutadas por e IPVDU en la provincia de Tucumán. Fuente: IPVDU.
PRO.CO.VI; Emergencia habitacional; Plurianual; Programa Federal de Integración Socio Comunitaria; Programa Federal de Urbanización de Villas: FED VILLAS; PRO MAT; Emergencia hídrica; PRO ME VI (en dos modalidades: a través de empresa o con cooperativas) y Mejor Vivir I y II.

Del total de obras realizadas puede observarse cómo en general, las obras destinadas a infraestructura tienden a centralizar la población de modo de cubrir un mayor número de familias siendo la modalidad de lote con servicio una de las políticas más implementadas. Estas tienen como finalidad mejorar la calidad de vida y contribuir a la inclusión espacial y social de los hogares de los segmentos más pobres de la población, a partir del mejoramiento sustentable del hábitat. En este senti-

\begin{tabular}{|c|c|c|c|c|c|c|}
\hline & Programas & Obras & Viviendas & Mejoras & $\begin{array}{l}\text { Obras de } \\
\text { infraestructura }\end{array}$ & $\begin{array}{l}\text { Familias } \\
\text { beneficiadas }\end{array}$ \\
\hline \multirow{8}{*}{ 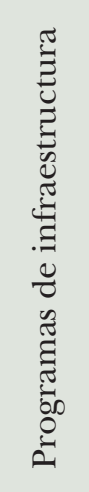 } & Recursos propios & 5 & & & 594 & \\
\hline & Pro.Me.Ba 1 & 7 & 84 & & 2314 & 8844 \\
\hline & Pro.Me.Ba transición & 4 & & & 722 & \\
\hline & Pro.Me.Ba 2 & 2 & & & 623 & \\
\hline & Sub programa Lomas & 4 & & & 5000 & \\
\hline & Techo digno & 2 & & & & \\
\hline & Fondo Fiducidiario & 2 & & & 311 & \\
\hline & Fondos especiales & 1 & & & 447 & \\
\hline \multirow{11}{*}{ 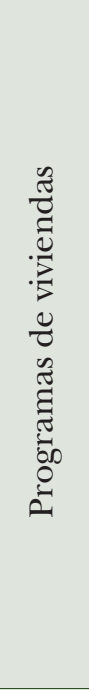 } & Reactivación I & 13 & 840 & & & 840 \\
\hline & Reactivación II & 4 & 150 & & & 150 \\
\hline & Recursos propios & 28 & 1085 & & & 1085 \\
\hline & Solidaridad habitacional & 47 & 2098 & & & 2096 \\
\hline & PRO.CO.VI & 56 & 3382 & & & 3382 \\
\hline & Emergencia habitacional & 39 & 952 & & & 952 \\
\hline & Federal. Lomas & 21 & 4204 & & & 4204 \\
\hline & Plurianual & 36 & 4924 & & & 4924 \\
\hline & Prog. Integración & 11 & 188 & & & 188 \\
\hline & Techo digno & 21 & 1816 & & & 1816 \\
\hline & Fed Villas & 27 & 2424 & & & 2424 \\
\hline \multirow{9}{*}{ 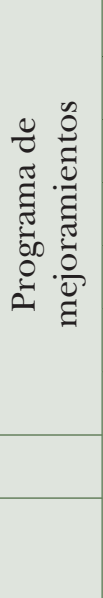 } & PRO.MAT & 20 & 968 & 174 & & 174 \\
\hline & Complemento PROMEBA & 19 & & 2139 & & 2139 \\
\hline & PRO.ME.VI $\left(1 .^{a}, 2 .^{a}\right.$ y $3 .^{a}$ etapa $)$ & 191 & & 19007 & & 19007 \\
\hline & Emergencia hídrica & 162 & & 12634 & & 12634 \\
\hline & PRO:ME:VI con cooperativas & 133 & & 4530 & & 4530 \\
\hline & Prog. Integración & 21 & & 1890 & & 1890 \\
\hline & Mejor Vivir & 35 & & 3150 & & 3150 \\
\hline & TOTAL PROVINCIAL & 911 & 23115 & 43524 & 3150 & 66668 \\
\hline & $\begin{array}{l}\text { Totales en las áreas rurales } \\
\text { consideradas }\end{array}$ & & 6000 & 14153 & & \\
\hline
\end{tabular}


do es que, mediante la ejecución de proyectos integrales barriales, se propone consolidar a la población destinataria en el lugar que habitan, brindando acceso a la propiedad de la tierra, contribuyendo en la provisión de obras de infraestructura urbana, equipamiento comunitario y saneamiento ambiental, y promoviendo el fortalecimiento de su capital humano y social. Por lo expuesto precedentemente, observamos que las obras ejecutadas en el interior de la provincia se localizan en la periferia de pueblos o centros de servicio rurales.

Respecto a la construcción de vivienda nueva, se observa en general que se trata de conjuntos medianos a pequeños, pero con prototipos idénticos a los urbanos de vivienda individual en lote de 10 por 30 metros de profundidad. En relación a las mejoras habitacionales, siguen en general el mismo patrón que las infraestructuras, concentrando la población para la provisión de agua, cloaca, o bien la construcción de un módulo habitacional. El efecto es el mismo, concentrar la población dispersa en el ámbito rural próxima a algún centro preexistente (Tabla 3).

En el año 2013, surge el Programa Federal de Vivienda y Mejoramiento del Hábitat de Pueblos Originarios y Rurales, como respuesta particular a la identidad y cultura de estos pueblos. El mismo surge de la articulación entre el IPVDU y la Secretaría de Agricultura Familiar y está compuesto por cuatro líneas: viviendas nuevas para pueblos originarios y rurales, mejoramiento de viviendas recuperables, obras de infraestructura rural y equipamiento productivo. Con respecto a la primera línea, como se puede ver a continuación (Figuras 4,5 y 6 ), se diseñaron tres prototipos de vivienda de dos y tres dormitorios, con cocina-comedor y baño. En aquellas que tenían tres dormitorios (Figuras 4 y 5 ) se puede observar que hay una mejor adaptación a algunas necesidades de la población rural ya que se realizan con galerías, sin embargo, las cocinas y materiales no se adaptan a las realidades locales y de producción campesina.

En el marco de este programa, se están ejecutando 5 proyectos en áreas rurales en el departamento de Monteros, Graneros, Trancas, Tafí del Valle y Leales que implican un total de 35 viviendas (Tabla 4).

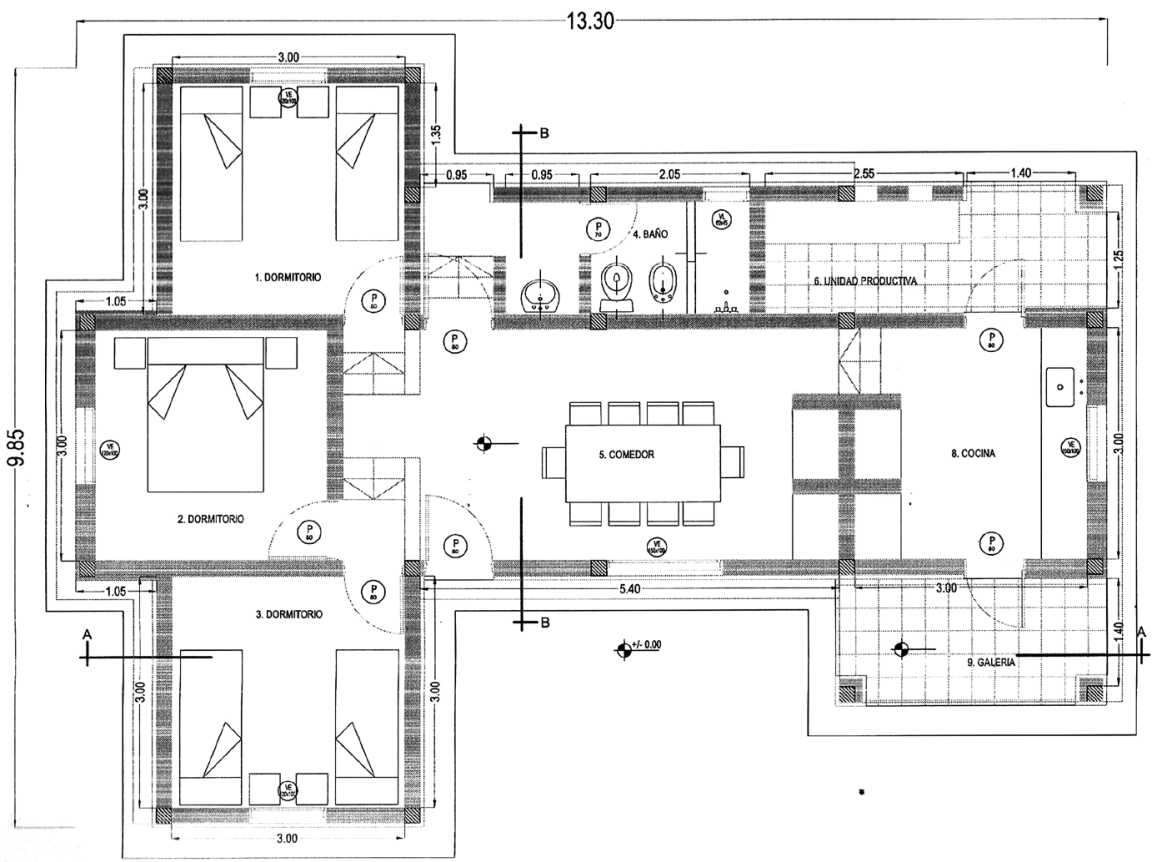

Figura 4: Prototipo de Vivienda Aborigen VA 1. Programa Federal de Vivienda y mejoramiento del hábitat de Pueblos Originarios y Rurales. Fuente: IPVDU. 
Figura 5: Prototipo de Vivienda Rural VR 1. Programa Federal de Vivienda y mejoramiento del hábitat de Pueblos Originarios y Rurales. Fuente: IPVDU.

Figura 6: Prototipo de Vivienda. Programa Federal de Vivienda y mejoramiento del hábitat de Pueblos Originarios y Rurales. Fuente: IPVDU.

Tabla 4: Programa Federal de Pueblos Originarios y Rurales. Etapa I: iniciadas enero 2014. Fuente: IPVDU.
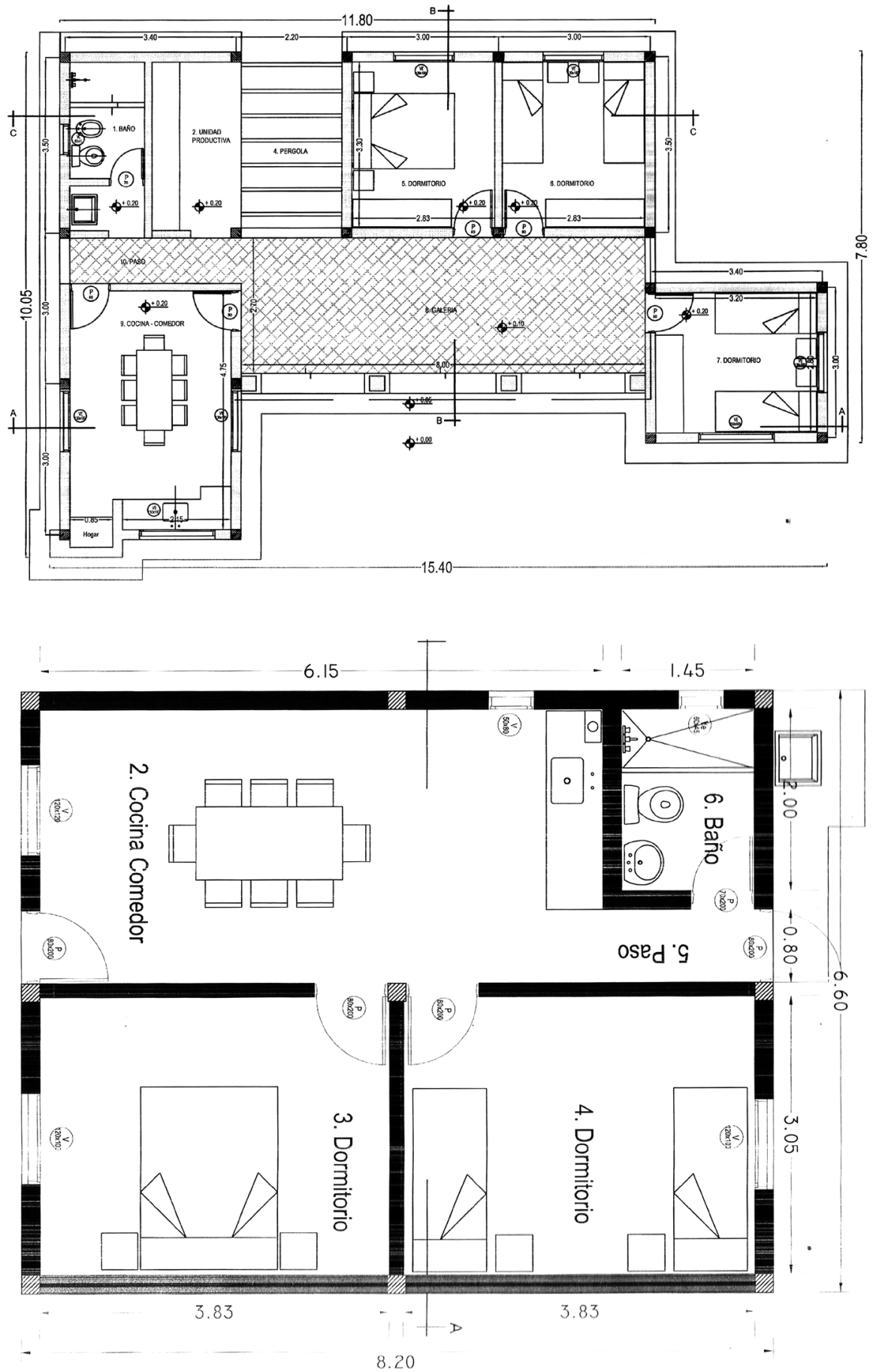

\begin{tabular}{|l|l|l|l|l|c|c|c|c|}
\hline SEOP & N. $^{\text {o }}$ & Obras & Departamento & Fondos & Monto Total & Viviendas & Mejora & M.O. \\
\hline 51220 & 1 & 8 Viv. León Rouges & Monteros & Nación & 1584000,00 & 6 & & 6 \\
\hline 21221 & 2 & $\begin{array}{l}\text { 2 Viv. San Pedro de } \\
\text { Colalao }\end{array}$ & Trancas & Nación & 396000,00 & 2 & & 2 \\
\hline 21222 & 3 & 7. Viv. Taco Ralo & Graneros & Nación & 1386000,00 & 7 & & 7 \\
\hline 21223 & 4 & $\begin{array}{l}15 \text { Viv. El Mollar } \\
\text { Mancopa }\end{array}$ & Tafí del Valle & Nación & 2970000,00 & 15 & & 15 \\
\hline & $\begin{array}{l}\text { SViv. Esquina y } \\
\text { OBRAS }\end{array}$ & Leales & Nación & 594000,00 & 5 & & 5 \\
\hline & & & 6930000,00 & 35 & & 35 \\
\hline
\end{tabular}


La implementación de esta línea tiene importantes avances en cuanto a la incorporación de las necesidades reales en tanto cantidad de personas que las habitan. Sin embargo, no incorpora materiales de construcción característicos y tampoco tiene en cuenta la opinión de la población con respecto a localización espacial dentro del predio ni a los modos de producción. Esto se puso en evidencia en el trabajo de campo particularmente en entrevistas realizadas en Taco Ralo, donde, por ejemplo, una familia rural beneficiada por un programa con una vivienda nueva decidió reacondicionar el antiguo rancho en el que habitaban. Esto se debe a que la estrecha y mínima cocina de la vivienda nueva no se adaptaba a las necesidades que requiere la producción artesanal de quesos con los que se sustentaba la economía familiar.

Por otro lado, el Programa de Vivienda Sociales no Tradicionales se desarrolla en el marco de un subprograma denominado PROMAT, el cual surge para consolidar el hábitat de las poblaciones del interior y frenar la migración hacia los centros urbanos. Estableciendo un sistema de autoconstrucción, se desarrollaron obras en distintas localidades de la provincia en zona de llanura: Granero, La Cocha, Taco Ralo, Simoca, Aguilares, Monteros, Bella Vista, Taruca Pampa, Delfín Gallo, Arcadia, Río Seco y en las zonas montañosas como Rodeo Grande, Potrero, Chuscha, La Higuera de Choromoro, San Pedro de Colalao y también en San Miguel de Tucumán. En este proceso se tuvieron en cuenta la diversidad de zonas climáticas, de costumbres y la opinión de los dueños de casa, por lo cual las características habitacionales y constructivas se fueron modificando. A fin de abaratar costos se trabajó con ladrillos de suelo cemento, block de cemento y adobes (IPVDU, 2013). Fueron beneficiarios de este programa en Tucumán más de 500 familias según detalle que se muestra en la Tabla 5. Cabe aclarar que este programa presenta a la fecha casi la mitad de las intervenciones aún en ejecución (Tabla 5).

\begin{tabular}{|l|c|c|}
\hline & Obras ejecutadas & En ejecución \\
\hline Viviendas & 131 & 132 \\
\hline Mejoras & 174 & 84 \\
\hline Familias beneficiadas & 305 & 216 \\
\hline
\end{tabular}

Otro programa destinado al mejoramiento del hábitat en áreas rurales es el Programa de Desarrollo Social en áreas fronterizas del NO y NE Argentino o PROFOSA. El mismo se implementó desde junio del 2015 y depende de la Secretaría de Infraestructura Urbana del Ministerio de Salud, destinándose a áreas urbanas, aglomerados rurales y colonias agrícolas. A través del mismo se financian proyectos para mejorar la cobertura y calidad en la provisión de agua y también infraestructura básica y social. En Tucumán se ejecutó a través del IPVDU con obras actualmente en ejecución en la localidad de Taco Ralo, al sur este de la provincia con la provisión de red de agua y pozos para 4200 familias (según informe IPVDU, página web).

\section{Consideraciones finales}

En las dos últimas décadas se produjo una importante diversificación de planes y programas de viviendas con el objeto de diversificar la oferta de soluciones tratando de cubrir la gran variedad de necesidades
Tabla 5: Obras Ejecutadas en la provincia de Tucumán, PROMAT. Fuente: IPVDU Tucumán. 
que presenta nuestro país. Si bien esto tendió a descentralizar la oferta desde el punto de vista de las políticas (Rodulfo y Boselli, 2015), esto no funcionó satisfactoriamente en el territorio de la provincia de Tucumán. Se debió básicamente a dos cuestiones: por un lado, la escasa magnitud de las realizaciones y, por otro lado, la falta de adecuación de las mismas a la realidad local de las comunidades.

Como se puede observar, las soluciones y respuestas que vienen implementándose, con algunas variantes de intensidad y enfoque de una u otra gestión de gobierno, son tema de fuerte preocupación, por su insuficiencia cuantitativa e inadecuación cualitativa, en diversos ámbitos (Pelli, 2015). A pesar de reconocerse en la provincia algunos procesos particulares que implementan la participación del usuario en el diseño de su hábitat, predomina en la historia de promoción pública de vivienda en Tucumán la adopción de soluciones estereotipadas, estándares que responden a la concepción de la vivienda como un producto, promoviendo la erradicación de ranchos, generando procesos de urbanización y sedentarización de la población, rompiendo con las culturas y la noción de familia extensa, y evitando así una política de mejora integral del hábitat.

Particularmente en los medios rurales, la implementación de políticas con sesgo urbano no solo vulnera un derecho al reconocimiento de la diferencia sino que además tiene su correlato en la pérdida de costumbres, el despojo de la tierra por parte de los campesinos y en consecuencia la mayor concentración de la misma, lo cual tiene un gran impacto en las comunidades rurales ya que este es el medio por el cual se garantiza la supervivencia y la reproducción de los campesinos en su propio hábitat, consolidando sus actividades productivas, su identidad y evitando la pérdida de los modos de producción contrahegemónicos (Garay, 2018).

Aun cuando diversos autores han asegurado que el problema de la vinchuca podría mejorarse prestando atención a las terminaciones y encuentros entre los diferentes materiales (Cejas, 2020; Di Lullo y Garay, 1969), desde la creación de la Comisión Nacional de Casas Baratas en 1942 el rancho se caracterizó como el modo de producción de la vivienda "pobre", vinculado principalmente con la enfermedad de Chagas. Así, en lugar de fomentar el "encuentro de saberes", que permita mejorar las técnicas de los campesinos para disminuir las enfermedades antes mencionadas sin perder las costumbres de estos, se impuso un modelo hegemónico de viviendas con materiales (ladrillo, hormigón y hierro), creando una nueva necesidad que aumentó la dependencia de los pobladores hacia el mercado, ya que impedía la autoconstrucción en su totalidad.

Lo analizado con respecto a la producción de vivienda en Tucumán, a partir de la creación del IPVDU en 1969 o más recientemente en 2013 con el "Programa Federal de Vivienda y Mejoramiento del Hábitat de Pueblos Originarios y Rurales", permite observar que este panorama no cambió, que la producción de vivienda estatal continúa focalizada en realizar obras con características urbanas y que no se diferenciaran hacia el interior rural de la provincia. En el último caso, su contextualización quedó como una expresión de anhelo en el nombre del programa que también se desarrolló desde una lógica de producción de vivienda de mercado adoptando la misma materialidad y propuestas tipológicas que la vivienda urbana, sin consideración y adecuación respecto a los saberes y necesidades de la población destinataria. 
A su vez, estas tipologías se convierten en un ideal de progreso ya que, como se pudo observar en el trabajo de campo, la humildad de las construcciones de adobe es una característica "de precariedad" en los discursos de los pobladores: "Mi casa antes era de tipo humilde, ¿ha visto? De adobe, pero bien hechita" (entrevista 06/07/17). Y aunque se considera que las viviendas construidas por el Estado son mejores en tanto son más lindas y no eran para sus pueblos: "Las casas no eran para aquí parece... son muy lindas" (entrevista 06/07/17), cuando se comienza a indagar sobre sus vidas anteriores y viviendas, hay una nostalgia por la vida que dejaron, el trabajo en las huertas y los corrales criando sus animales, la casa fresca de adobe y el aire puro del patio.

En este sentido, y sin ánimo de desvalorizar los esfuerzos y los avances que se realizaron por mejorar las condiciones de vida de las poblaciones, en cuanto a salud, educación e infraestructura, se considera imprescindible exigir al Estado que recupere los saberes de las comunidades en tanto respondan a sus modos de vida y de habitar, y favorezcan el arraigo de estas a sus tierras disminuyendo la migración ruralurbana y los procesos de urbanización. 
Bolsi, Alfredo (2000). Población, azúcar e industria rural en Tucumán. Geographicalia, 38, 85-109.

Cejas, Noelia (2020). Para descolonizar el hábitat rural. Un análisis de la matriz colonial de las políticas públicas habitacionales en Córdoba (Argentina). Territorios, 43, 1-22. DOI: https:// doi.org/10.12804/revistas.urosario.edu.co/ territorios/a.8150.

Cuenya, Beatriz (1997). Entre la equidad y la sumisión del mercado. Propuestas y dilemas en torno a la Conferencia de las Naciones Unidas, Hábitat II (Estambul, Turquía, 1996). Estudios del Hábitat, 5, 158160. Recuperado el 20 de julio de 2021 de: http:/ / sedici.unlp.edu.ar/handle/10915/46167.

Di Lullo, Orestes y Garay, Luis (1969). La vivienda popular de Santiago del Estero. Tucumán: Facultad de Filosofía y Letras, Universidad Nacional de Tucumán.

Garay, Ana (2018). Hábitat rural y condiciones de vida en Tucumán (Tesis de doctorado). Facultad de Filosofía y Letras, Universidad Nacional de Tucumán, Argentina.

Garay, Ana (2019). Configuración del hábitat rural y condiciones de vida. Modelo conceptual para un abordaje relacional. Estudios del hábitat, 17(1), e064. DOI: $10.24215 / 24226483 \mathrm{e} 064$.

Gargantini, Daniela (2012). Revisión histórica de las politicas de vivienda argentinas implementadas como respuestas a la problemática sociohabitacional existente (documento online). Recuperado de http://blog.ucc. edu.ar/ssh/files/2012/Revision-historica-depoliticas-habitacionales_Gargantini.pdf.

Gargantini, Daniela (2020a). La situación socio-habitacional y los gobiernos locales. En Gestión local del hábitat: el acceso local a la vivienda tras el impacto COVID-19 (Apunte de curso de posgrado). Universidad Católica de Santa Fe, Argentina.

Gargantini, Daniela (2020b). Modos de gestión de la problemática sociohabitacional a nivel local. En Gestión local del hábitat: el acceso local a la vivienda tras el impacto COVID-19 (Apunte de curso de posgrado). Universidad Católica de Santa Fe, Argentina.

Giarracca, Norma y Teubal, Miguel (2006). Democracia y neoliberalismo en el campo argentino. Una convivencia difícil. En Grammont, Hubert (Ed.), La construcción de la democracia en el campo latinoamericano (pp. 69-94). Buenos Aires: CLACSO.

Gómez López, Roberto et al. (1994). Directrices para el Ordenamiento del Territorio de la provincia de Tucumán. Tucumán: Convenio Gob. dela Provincia de Tucumán, MOPyT (España) y UNT.

Graglia, Emilio (2004). Políticas públicas: fases y fallas como proceso de satisfacción social. STUDIA POLITICAE, 3. 49-77.
Krapovickas, Julieta y Garay, Ana (2017) Una aproximación descriptiva a la desigualdad socio-territorial en ámbitos rurales del Noroeste Argentino en la primera década del siglo xxi. Estudios Geográficos, 78(283), 605-632. DOI: https://doi.org/10.3989/ estgeogr.201721.

Longhi, Fernando; Bolsi, Alfredo; Paolasso, Pablo; Velázquez, Guillermo y Celemín, Juan Pablo (2013). Fragmentación socio-territorial y condiciones de vida en la Argentina. Revista Latinoamericana de población, 7(12), 99-131.

López de Albornoz, Cristina (1998). Control social y economía tucumana. Las ordenanzas de buen gobierno y el conchabo obligatorio a fines del siglo xviII. Travesía, 1, 63-116.

Lucero, Patricia, Riviere, Isabel, Mikkelsen, Claudia y Sabuda, Fernando (2005). Brechas socioterritoriales vinculadas con la Calidad de Vida en Mar del Plata. En Velázquez, Guillermo y Gómez Lende, Sebastián (Ed.). Desigualdad y Calidad de Vida en la Argentina (1991-001). Aportes empiricos y metodológicos (pp. 319-360). Tandil: UNCPBA.

Mendióroz, Carlos (1942). Tucumán y su vivienda rural. En La habitación popular. Órgano oficial de la Comisión Nacional de Casas Baratas. Año VIII, n. ${ }^{\circ}$ 30-31 (pp. 9-40). Buenos Aires: Talleres gráficos Tomás Palumbo.

Ortiz de D’Arterio, Patricia (2017a). La población de Tucumán: una visión de conjunto. En Ortiz de D’Arterio, Patricia (Ed.). La población: su dinámica y los retratos resultantes. Colección historias temáticas de Tucumán, siglos XIX y XX (pp. 1-21). Buenos Aires: Imago Mundi.

Ortiz de D'Arterio, Patricia (2017b). La inmigración de ultramar. En Ortiz de D'Arterio, Patricia (Ed.). La población: su dinámica y los retratos resultantes. Colección historias temáticas de Tucumán, siglos XIX y XX (pp. 161-186). Buenos Aires: Imago Mundi.

Ortiz Bergia, María José y Salomón, Alejandra (2017). Estado y bienestar rural argentino en la primera mitad del siglo xx. Un problema historiográfico. Historia Caribe, 12(31), 19-44. DOI: http://dx.doi. org/10.15648/hc.31.2017.2.

Osatinsky, Ariel (2017). Población ocupada, problemas de empleo, y condiciones de vida en Catamarca y Tucumán (1880-1970). Perspectivas $M e^{-}$ todológicas, 17(20), 111-133. DOI: https://doi. org/10.18294/pm.2017.1660.

Oszlak, Oscar y O’Donnell, Guillermo (2007). Estado y políticas estatales en América Latina: hacia una estrategia de investigación. En Acuña, Carlos H. (Ed.). Lecturas sobre el Estado y las políticas públicas: Retomando el debate de ayer para fortalecer el actual (pp. 
555-583). Ciudad Autónoma de Buenos Aires: Proyecto de Modernización del Estado-Jefatura de Gabinete de Ministros de la Nación.

Paolasso, Pablo (2004). Los cambios en la distribución espacial de la población de Tucumán durante el siglo XX (Tesis doctoral). Facultad de Filosofía y Letras, Universidad Nacional de Tucumán, Tucumán, Argentina.

Paz, Raúl (2006). El campesinado en el agro argentino: ¿repensando el debate teórico o un intento de reconceptualización? European Review of Latin American and Caribbean Studies, 81, 65-85. DOI: http:/ / doi.org/10.18352/erlacs.9648.

Pelli, Víctor (2015). Prólogo. En Barreto, Miguel Ángel y Lentini, Mercedes, Hacia una politica integral del hábitat. Aportes para un observatorio de política habitacional en Argentina (pp. 7-14). Buenos Aires: Café de las ciudades.

Quevedo, Cecilia (2014). Cuando "reconocer" es entregar "viviendas". Pueblos indígenas y entornos de la inclusión/exclusión chaqueña. Revista Cuestiones de Población y Sociedad, 4(4), 35-48.

Rivas, Ana Isabel, Aguilar, Ana Gabriela y Ale, María Jimena (2016). De parajes a pueblos rurales planificados: nuevas territorialidades en el Pedemonte tucumano. En López, Cristina y Rivas, Ana Isabel, Asentamientos y pueblos rurales de Tucumán. Entre la colonia y el bicentenario (pp. 107-128). Tucumán: Universidad Nacional de Tucumán, Facultad de Filosofía y Letras.

Rodulfo, María Beatriz et al. (2000). Desarrollo Integral del Hábitat. Vivienda y reconversiones productivas de minifundios. En CYTED-HABYTED (Ed.), Memoria del II Seminario y Taller Iberoamericano sobre Vivienda Rural y calidad de vida en los asentamientos rurales (pp. 133-141). San Luis de Potosí (México): Editorial Universitaria Potosina.

Rodulfo, María Beatriz y Boselli, Teresa (2015). Política Habitacional en Argentina y desigualdades territoriales. Vivienda y Ciudad, 2, 30-41. Recuperado el 20 de julio de 2021 de: https:/ / revistas.unc.edu.ar/ index.php/ReViyCi/article/view/13173.

Romero, Rocío (2017). El departamento de Burruyacu en el siglo xIx. En Romero, Rocío y Ragone, Lucila, Historia del Municipio de Burruyacu. Colección historia de los municipios de Tucumán (pp. 49-89). Buenos Aires: Imago Mundi.

Romero, Rocío y Ragone, Lucila (2017). Las transformaciones de Burruyacu en la segunda mitad del siglo xx. En Romero, Rocío y Ragone, Lucila, Historia del Municipio de Burruyacu. Colección historia de los municipios de Tucumán (pp. 130-183). Buenos Aires: Imago Mundi.

Sánchez Quintanar, Concepción y Jiménez Rosas, Eric Orlando (2010). La vivienda rural. Su complejidad y estudio desde diversas disciplinas. Revista Luna Azul, 30, 174-196. Recuperado el 20 de julio de 2021 de: http://www.scielo.org.co/pdf/luaz/n30/ n30a10.pdf.

Segura, Ramiro (2020). El espacio urbano y la (re) producción de desigualdades sociales. Desacoples entre distribución del ingreso y patrones de urbanización en ciudades latinoamericanas. En Jelin, Elizabeth, Motta, Renata y Costa, Sergio (Ed.). Repensar las desigualdades. Cómo se producen y entrelazan las asimetrías globales (y qué hace la gente con eso) (pp. 89110). Buenos Aires: Siglo xxi Editores.

Yujnovsky, Óscar (1971). La estructura interna de la ciudad. El caso Latinoamericano. Buenos Aires: Ediciones SIAP.

Garay, Ana y Gómez López, Claudia Fernanda (2021). Una aproximación al estudio de las políticas públicas de vivienda rural en Tucumán. Hábitat y Sociedad, 14, 303-323.

<https://doi.org/10.12795/HabitatySociedad.2021.i14.16> 


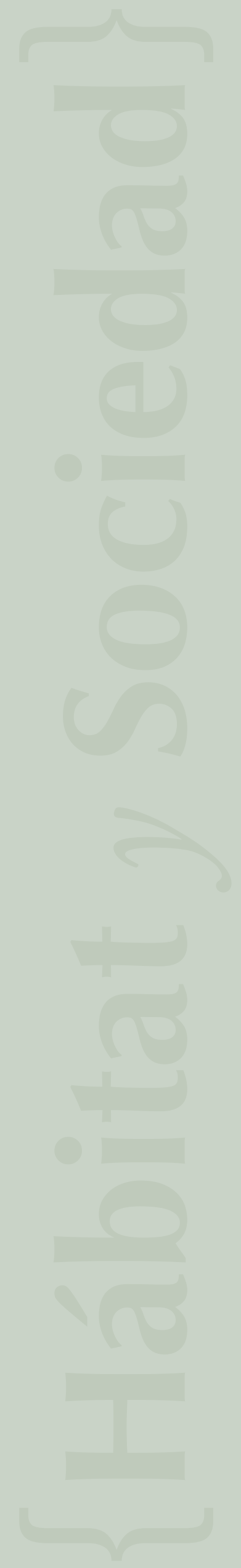

